\title{
Overexpression of RKIP Inhibits Cell Invasion in Glioma Cell Lines through Upregulation of miR-98
}

\author{
Zigui Chen, Quan Cheng, Zhiming Ma, Haipeng Xi, Renjun Peng, and Bing Jiang \\ Department of Neurosurgery, Xiangya Hospital, Central South University, Changsha, Hunan 410011, China \\ Correspondence should be addressed to Bing Jiang; zgxyjiangbing@hotmail.com
}

Received 9 March 2013; Revised 13 June 2013; Accepted 17 June 2013

Academic Editor: William S. Trimble

Copyright (C) 2013 Zigui Chen et al. This is an open access article distributed under the Creative Commons Attribution License, which permits unrestricted use, distribution, and reproduction in any medium, provided the original work is properly cited.

\begin{abstract}
Raf-1 kinase inhibitor protein (RKIP) is a tumor and metastasis suppressor in cancer cells. MicroRNAs (miRNAs) have been suggested to play a vital role in tumor initiation and progression by negatively regulating oncogenes and tumor suppressors. Quite recently, studies have identified some miRNAs operating to promote or suppress tumor invasion or metastasis via regulating metastasis-related genes, providing potential therapeutic targets on antimetastasis strategy. In this study, we found that the expression of RKIP and miR-98 in glioma tissues were significantly lower than that in normal brain tissues. Overexpression of RKIP upregulated miR-98 expression and inhibited glioma cell invasion and miR-98 target gene HMGA2 but had no effect in glioma cell proliferation. Moreover, forced expression of miR-98 accelerated the inhibition of glioma cell invasion and the expression of HMGA2 also had no effect in glioma cell proliferation. Our findings newly described RKIP/miR-98 to HMGA2 link and provided a potential mechanism for glioma cell invasion. RKIP and miR-98 may illustrate the potential therapeutic utility of signaling pathway signatures.
\end{abstract}

\section{Introduction}

Gliomas are the most common primary brain tumors [1]. Ras signaling was found to be required for the maintenance of glioma tumor growth in vivo [2]. Recent results indicate that Ras/Raf/MAPK pathway activation in glioma is achieved much more frequently by copy number gains than by mutations [3]. Interestingly, a Ras inhibitor can block both glioma cell migration and anchorage-independent proliferation [4]. Furthermore, a combination of Raf and mTOR inhibitors reduces glioma cell proliferation and invasion [5]. Raf kinase inhibitory protein (RKIP), also known as phosphatidylethanolamine binding protein, is involved in regulation of growth and differentiation of mammalian cells by inhibiting Raf and thereby negatively regulating growth factor signaling by the Ras/Raf/MAPK signal transduction pathway [6-8]. Lack of RKIP has been shown to promote tumor progression in a variety of human cancers [7].

A recent report has identified the critical role of RKIP in induction of let-7/miR-98. RKIP represses invasion, intravasation, and bone metastasis of breast tumor cells through a signaling cascade involving inhibition of MAPK, Myc, and LIN28 which leads to induction of the microRNA let7/miR-98 and downregulation of its target genes $[9,10]$. Nevertheless, the biological link of RKIP/miR-98 in the malignant progression of gliomas remains to be elucidated.

High mobility group protein A2 (high mobility group A2, (HMGA2)) as one of miR-98 target genes [11] is a recently discovered nonhistone chromatin protein, which is closely related to tumorigenesis, invasion, and metastasis of tumors, which have high extent and levels of expression in epithelial or interstitial malignant and are dependent on the metastasis of malignant and have poor prognosis [12-17].

In the present study, we confirmed the regulatory relationship between RKIP, an antioncogene and a known tumor suppressive miRNA, and miR-98. We provided lines of evidences that over-expression of RKIP could inhibit glioma cell invasion at least partly through upregulation of miR-98.

\section{Materials and Methods}

2.1. Human Tissue Samples. All human normal brain and glioma tissue samples were obtained from the Department 


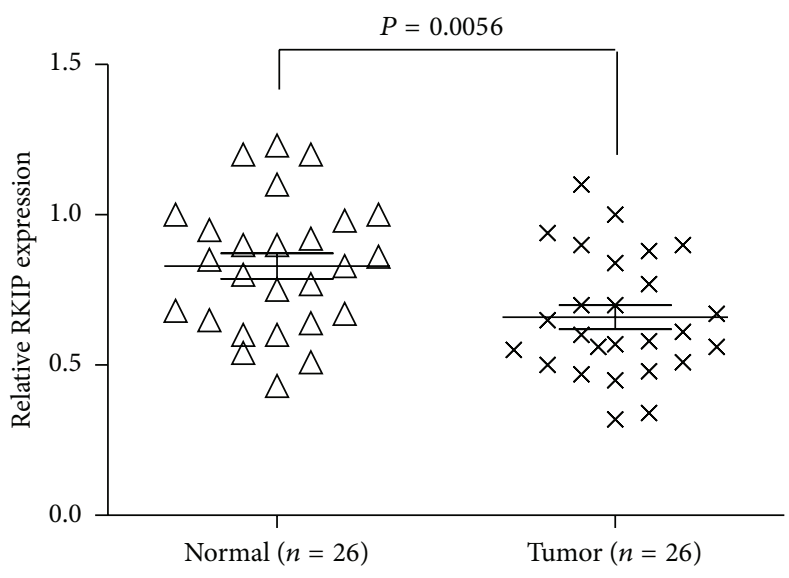

(a)

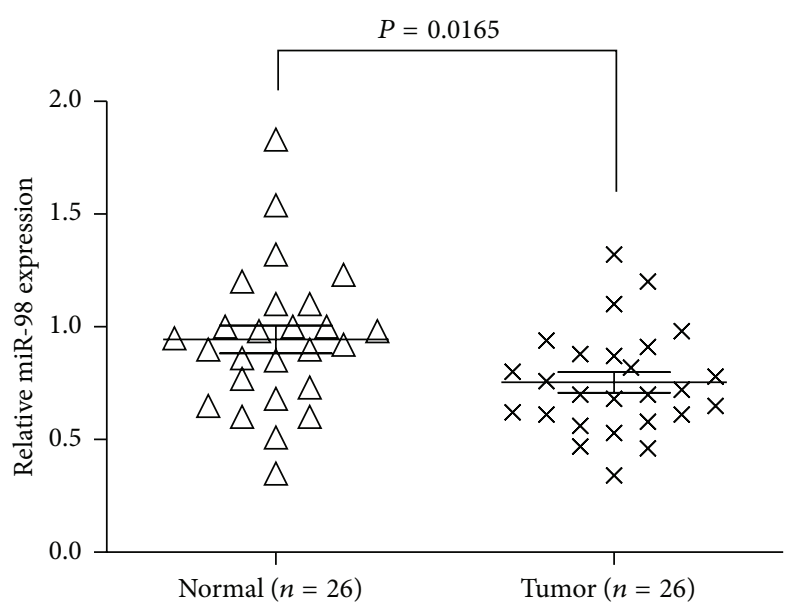

(c)

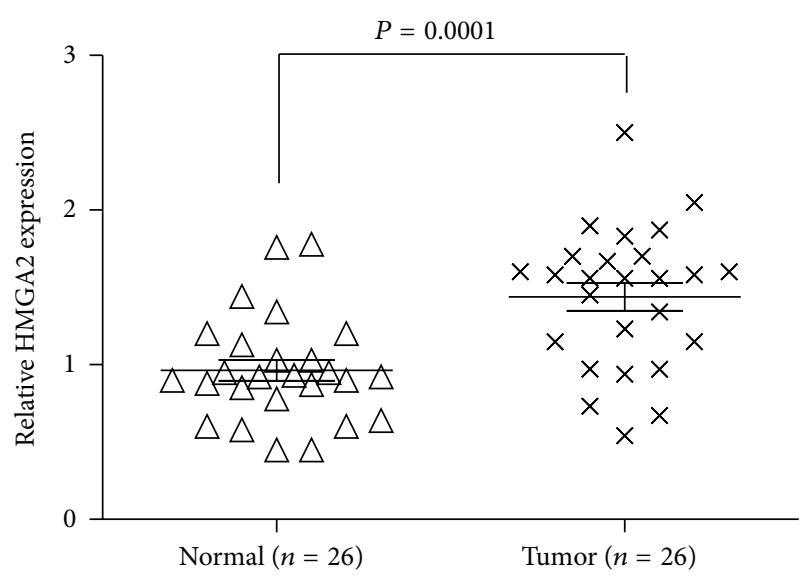

(b)

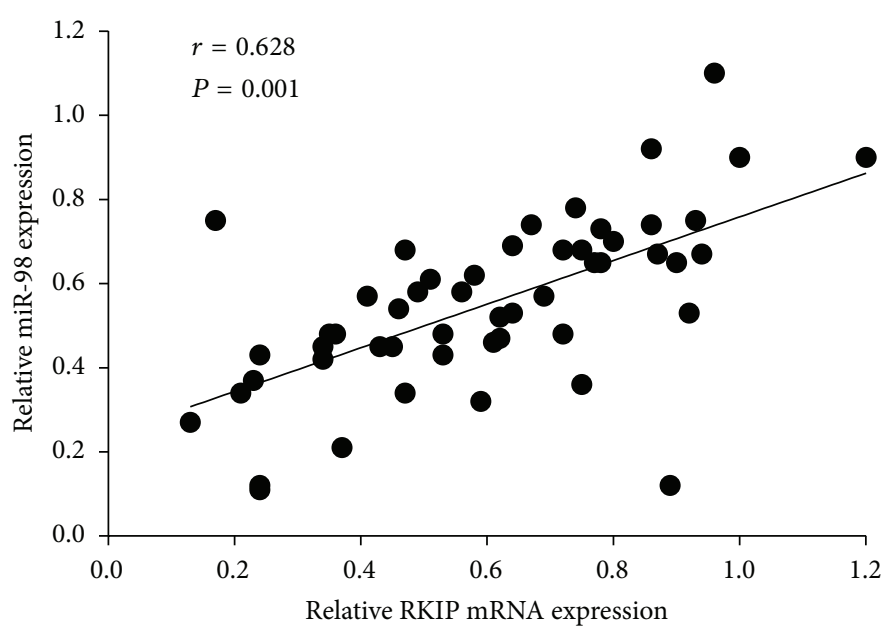

(d)

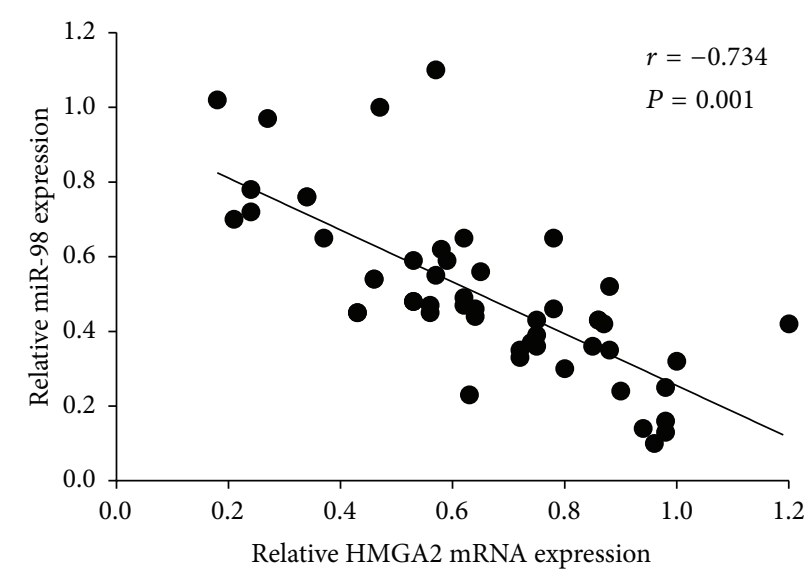

(e)

FIGURE 1: The miR-98 levels were positively correlated with the RKIP mRNA levels and negatively correlated with the HMGA2 mRNA levels in gliomas tissues. ((a), (b), (c)) The expression of RKIP mRNA, HMGA2 mRNA, and miR-98 was tested by quantitative RT-PCR in gliomas tissues compared to the adjacent normal brain tissues in a panel of matched tissues from 26 glioma patients (Wilcoxon's paired test, $P$ values shown in the figures). ((d), (e)) Dot plots represent RKIP (HMGA2) mRNA relative expression level against miR-98 relative expression level. The lines represent approximated curves. The correlation coefficient $(r)$ and the $P$ value indicate the statistical significance of the negative correlation between the $x$ and $y$ variables. Results showed that the expression of miR-98 was positively correlated with RKIP mRNA and negatively correlated with HMGA2 mRNA. The figure is representative of three experiments with similar results. 


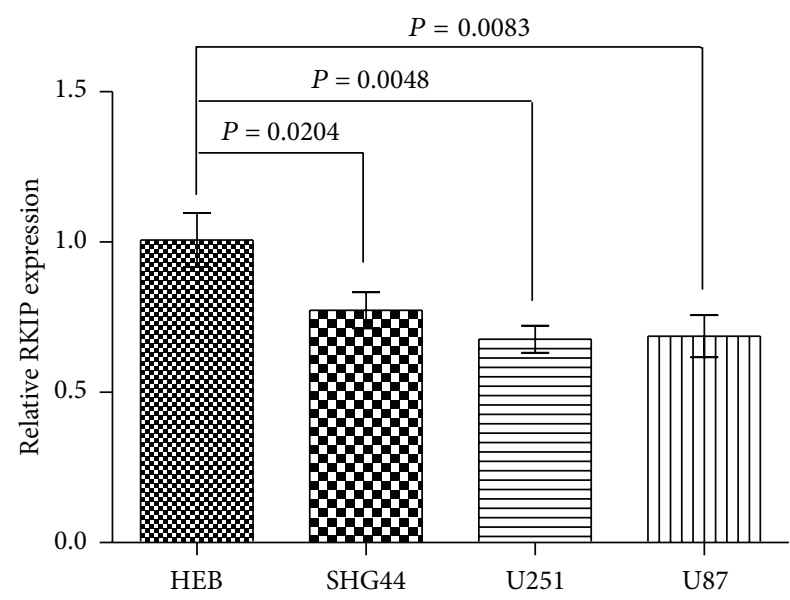

(a)

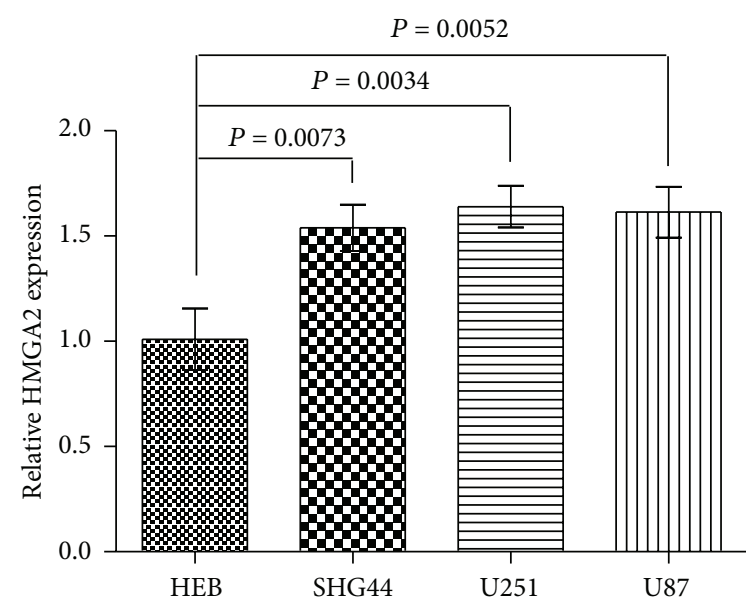

(b)

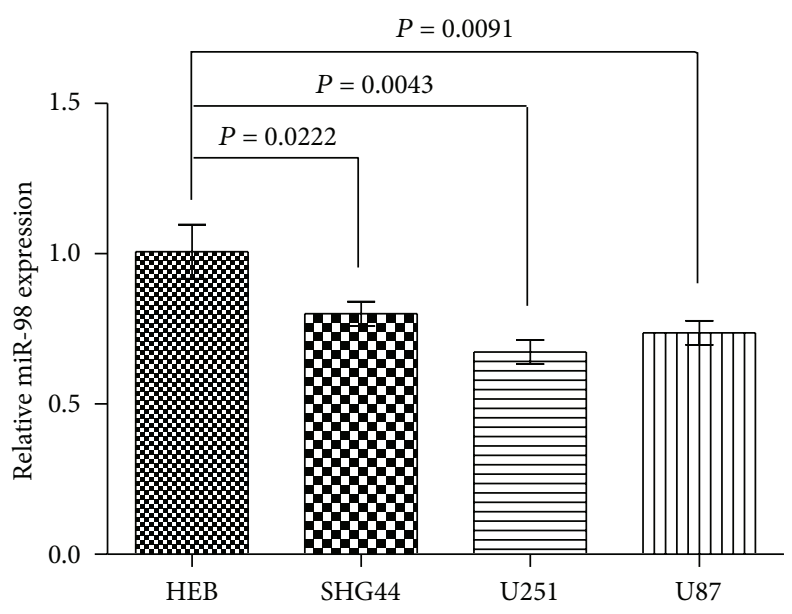

(c)

FIGURE 2: The RKIP mRNA levels, HMGA2 mRNA levels and miR-98 levels in glioma cells. ((a), (c)) Decreased expression of RKIP mRNA and miR-98 was tested by quantitative RT-PCR in glioma cells compared to the human glial cell HEB (Wilcoxon's paired test, $P$ values shown in the figures). (b) Increased expression of HMGA2 was tested by quantitative RT-PCR in glioma cells compared to the human glial cell HEB (Wilcoxon's paired test, $P$ values shown in the figures). The figure is representative of three experiments with similar results.

of Neurosurgery, Xiangya Hospital Central-South University. This study procedure was approved by The Institutional Review Board at the hospital. All participants provided written informed consent. Tissue samples were collected during surgery. For each sample, the major portion of tissue was frozen immediately in liquid nitrogen for molecular analysis, and the remaining tissue was fixed in paraformaldehyde for histological examination. All samples were histologically classified and graded according to WHO guidelines by a clinical pathologist, were prepared for cases in the institute biorepository, and classified and selected based on diagnosis.

\section{Cell Lines and Cell Transfection}

The human glial cell HEB and three human glioma cell lines, including U251, U87, and SHG44, were purchased from American Type Culture Collection. Cells were grown routinely in RPMI-1640 medium (Invitrogen, CA, USA) supplemented with $10 \%$ fetal bovine serum (Gibco, CA,
USA) and cultured in a $37^{\circ} \mathrm{C}$ humidified atmosphere of $5 \% \mathrm{CO}_{2}$. Ectopic expression of RKIP in cells was achieved by transfection with RKIP ORF clone (Neuron Bioscience, Shanghai, China) using Lipofectamine 2000 (Invitrogen, CA, USA). Overexpression of miR-98 was performed using primiR-98 (Neuron Bioscience, Shanghai, China). Cells were plated in 6-well clusters or 96-well plates and transfected for $24 \mathrm{~h}$ or $48 \mathrm{~h}$. Transfected cells were used in further assays or $\mathrm{RNA} /$ protein extraction.

3.1. RNA Extraction and SYBR Green Quantitative PCR Analysis. Total RNA was extracted from cells using Trizol reagent (Invitrogen, CA, USA). Mature miR-98 expressions in cells were detected using a Hairpin-it TM miRNAs qPCR kit (Genepharma, Shanghai, China). Expression of RNU6B was used as an endogenous control. RKIP expression was measured by SYBR green qPCR assay (Takara, Dalian, China). Data were processed using $2^{-\Delta \Delta C T}$ method. 


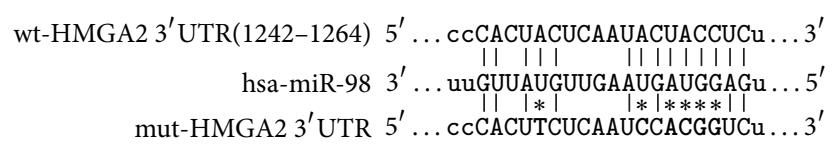

(a)

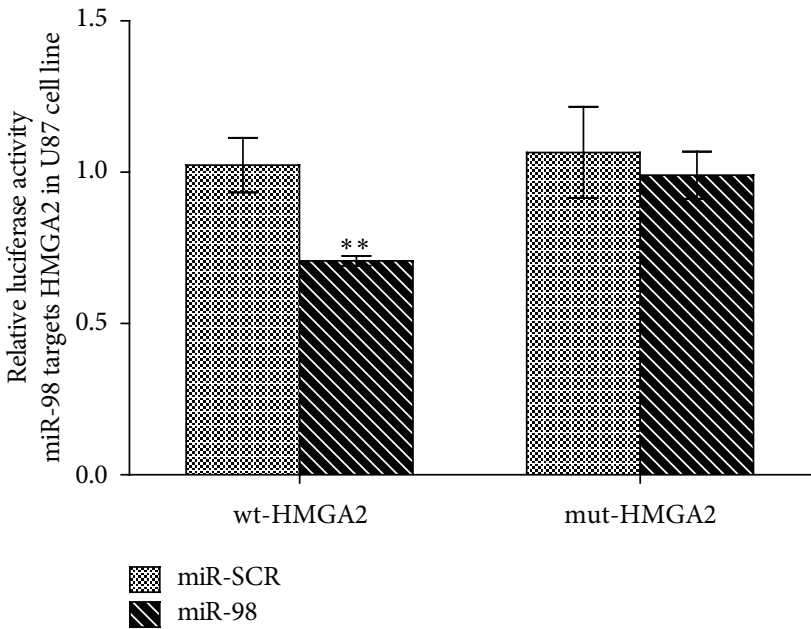

(b)

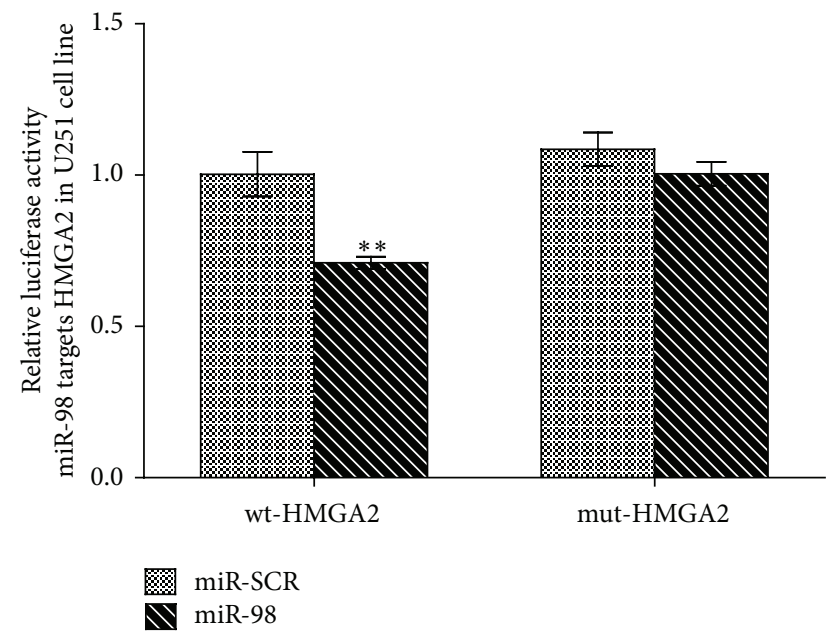

(c)

FIGURE 3: miR-98 directly targets HMGA2 by binding to its $3^{\prime}$ UTR. (a) The predicted miR-98 binding site within HMGA2 $3^{\prime}$ UTR and its mutated version by site mutagenesis are as shown. (b) The repression of luciferase activity by HMGA2 $3^{\prime} \mathrm{UTR}$ was dependent on miR-98 both in U251 and U87. Mutated HMGA2 3'UTR abrogated miR-98 mediated repression luciferase activity $\left({ }^{* *} P<0.01\right)$.

3.2. Luciferase Assay. U251 and U87 cells were seeded into a 24-well plate. After being cultured overnight, cells were cotransfected with the wild-type and mutated HMGA2 $3^{\prime}$ UTR reporter plasmid and pRL-TK plasmids or transfected with miR-98 and miR-scrambled control precursors (miR-SCR). Luciferase assays were performed $48 \mathrm{~h}$ after transfection using the Dual Luciferase Reporter Assay System (Promega, WI, USA).

3.3. Western Blot Analysis. Immunoblotting was performed to detect the expression of RKIP and HMGA2 in glioma cell lines. Cultured or transfected cells were lysed in RIPA buffer with $1 \%$ PMSF. Protein was loaded onto a SDSPAGE minigel and transferred onto PVDF membrane. After probed with 1:1000 diluted rabbit polyclonal RKIP and HMGA2 antibody (Abcam, MA, USA) at $4^{\circ} \mathrm{C}$ overnight, the blots were subsequently incubated with HRP-conjugated secondary antibody $(1: 5000)$. Signals were visualized using ECL substrates (Millipore, MA, USA). B-Actin was used as an endogenous protein for normalization.

3.4. BrdU Incorporation Assay. DNA synthesis in proliferating cells was determined by measuring 5-bromo-2deoxyuridine (BrdU) incorporation. BrdU assays were performed at $24 \mathrm{~h}$ and $48 \mathrm{~h}$ after transfecting U251 or U87 cells with RKIP or control vector. The transfected cells were seeded in 96-well culture plates at a density of $2 \times$ $10^{3}$ cells/well, cultured for $24 \mathrm{~h}$ or $48 \mathrm{~h}$, and incubated with a final concentration of $10 \mu \mathrm{M}$ BrdU (BD Pharmingen, San Diego, CA, USA) for $2 \mathrm{~h}$ to $24 \mathrm{~h}$. At the end of the incubation period, the medium was removed, the cells were fixed for $30 \mathrm{~min}$ at RT, incubated with peroxidase-coupled anti-BrdU antibody (Sigma-Aldrich) for $60 \mathrm{~min}$ at RT, washed three times with PBS, and incubated with peroxidase substrate (tetramethylbenzidine) for $30 \mathrm{~min}$, and the absorbance values were measured at $490 \mathrm{~nm}$. Background BrdU immunofluorescence was determined in cells not exposed to BrdU but stained with the BrdU antibody.

3.5. Cell Invasion Assay. The invasive potential of cells was evaluated using transwell inserts with $8 \mu \mathrm{m}$ pores (Coring, NY, USA). For invasion assay, at $24 \mathrm{~h}$ after transfection, $2.0 \times$ $10^{5}$ cells (for Figure 6 ) and $1 \times 10^{6}$ cells (for Figure 7) in serum free medium were added to each upper insert pre-coated with matrigel matrix (BD, NJ, USA). $500 \mu \mathrm{L} \mathrm{10 \%} \mathrm{FBS} \mathrm{medium} \mathrm{was}$ added to the matched lower chamber. After $48 \mathrm{~h}$ incubation, noninvaded cells were removed from the upper surface of the Transwell membrane with a cotton swab, and invaded cells on the lower membrane surface were fixed in methanol, stained with $0.1 \%$ crystal violet, photographed, and counted. Inserts were conducted in triplicate in three separate experiments.

3.6. Statistical Analysis. All data from 3 independent experiments were expressed as mean \pm SD and processed using SPSS17.0 statistical software. The expression of RKIP and miR-98 in glioma tissues and paired adjacent normal glial tissues was compared by Wilcoxon's paired test. A $P$ value of $<0.05$ was considered to be statistically significant. 


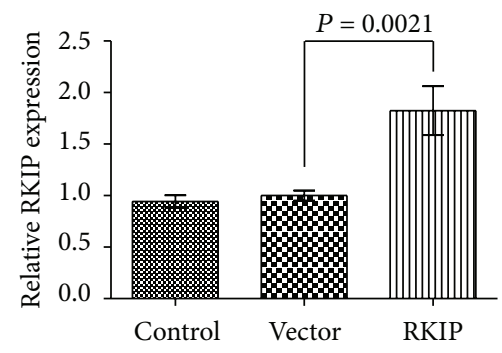

(a)

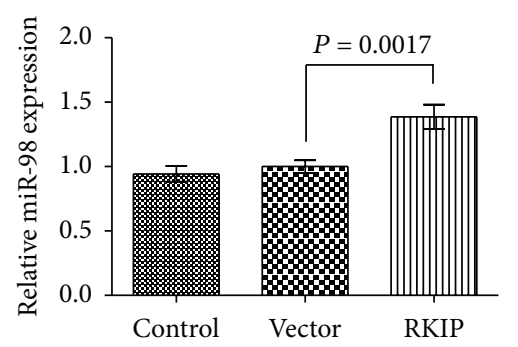

(d)

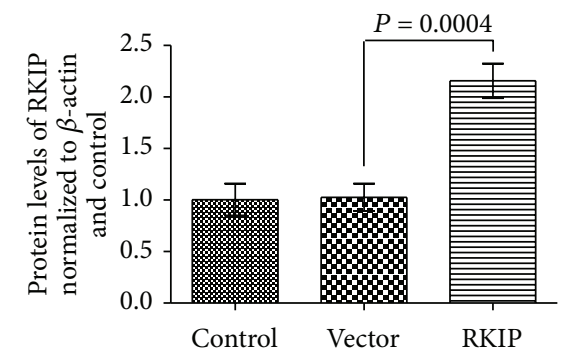

(g)

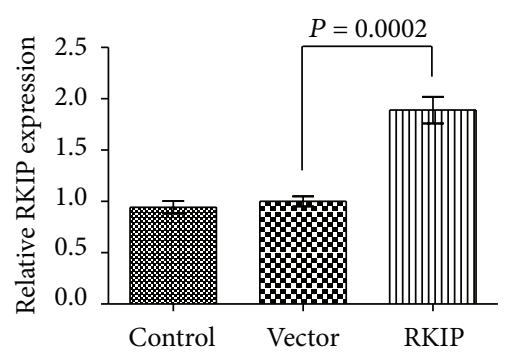

(b)
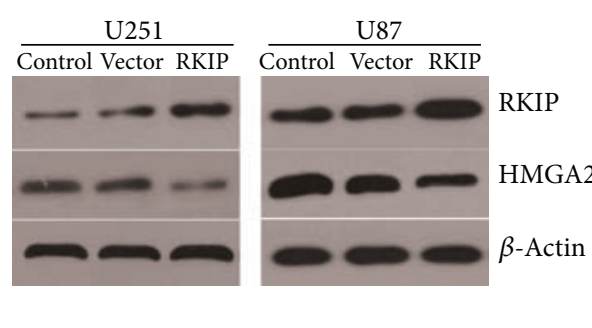

(e)

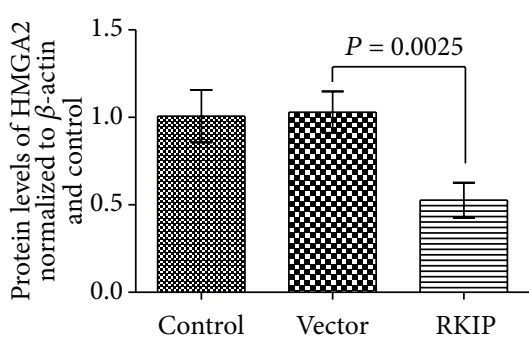

(h)

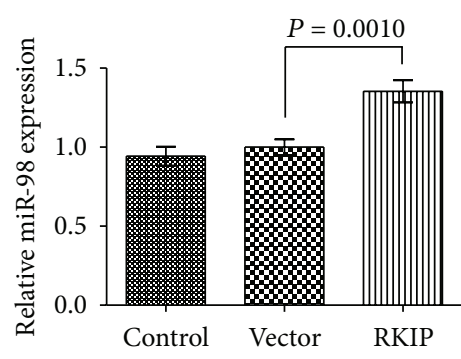

(c)

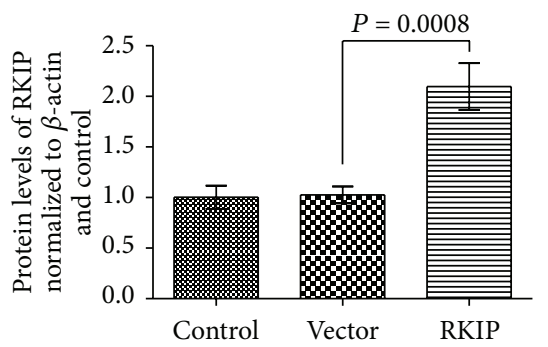

(f)

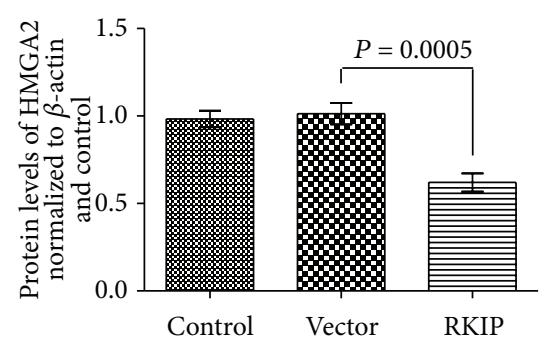

(i)

FIGURE 4: Force expression of RKIP enhances miR-98 expression and inhibits HMGA2 expression. U251 or U87 cells were stably infected with vector control and RKIP ORF clone. ((a), (b)) Quantitative RT-PCR quantification of RKIP mRNA or miR-98 expression compared to U251 or U87 cells transfected with vector control. (c) Western blot of RKIP protein expression. Expression of RKIP was forced, and expression of HMGA2 was inhibited by overexpression of RKIP, compared to U251 or U87 cells expressing vector. ((d), (e)) Band intensities were quantitated by Image-Pro Plus. The intensities of the bands corresponding to RKIP and HMGA2 were compared to those corresponding to $\beta$-actin and control untransfected U251 or U87. The figure is representative of three experiments with similar results.

\section{Results}

4.1. The miR-98 Levels Were Positively Correlated with the RKIP $m R N A$ Levels and Negatively Correlated with the HMGA2 mRNA Levels in Glioma Tissues and Cell Lines. We performed SYBR green quantitative PCR analysis to detect the expression level of RKIP, HMGA2, and miR-98 in glioma tissues and cell lines. In the large panel of 26 cases of primary glioma tissues and their adjacent normal glial tissues, our results showed that miR-98 was significantly decreased in 21 (81\%) in glioma tissues and RKIP in 19 (73\%) and HGMA2 increased in $22(85 \%)$ when compared with that in the paired adjacent normal tissues (Figures 1(a), 1(b), and 1(c)). Moreover, the expression of miR-98 was positively correlated with RKIP relative expression and negatively correlated with HMGA2 in tumor tissues (Figures $1(\mathrm{~d})$ and $1(\mathrm{e})$ ). In addition, we extended our test to one human glial cell and three human glioma cell lines. The total three cell lines showed a notable low expression of miR-98 and RKIP and high expression of
HMGA2, whereas the control human glial cell expressed a strong level of it (Figures 2(a)-2(c)). These results suggested miR-98 levels positively correlated to the levels of RKIP expression and negatively correlated to the levels of HMGA2 expression in glioma tissues and cell lines.

4.2. miR-98 Directly Targets HMGA2. The combining sites of HMGA2 $3^{\prime}$ UTR with miR-98 were predicted by TargetScan and microRNA.org. A sequential replacement of a 6-base pair region was performed to produce mutant vector. (Figure 3(a)). To further investigate if the predicted binding site of miR-98 to $3^{\prime}$ UTR of HMGA2 is responsible for this regulation, we cloned the $3^{\prime}$ UTR of HMGA2 downstream to a luciferase reporter gene (wt-HMGA2); its mutant version (mut-HMGA2) by the binding site mutagenesis was also constructed. We cotransfected wt-HMGA2 vector and miR98 mimics or scramble control into U251 and U87 cells. The luciferase activity of miR-98 transfected cells was significantly reduced compared to scramble control cells (Figure 3(b)). 


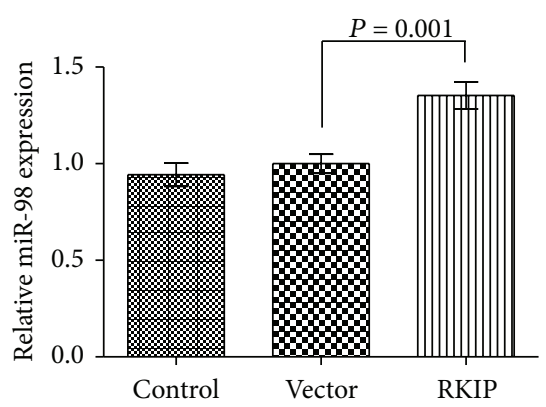

(a)

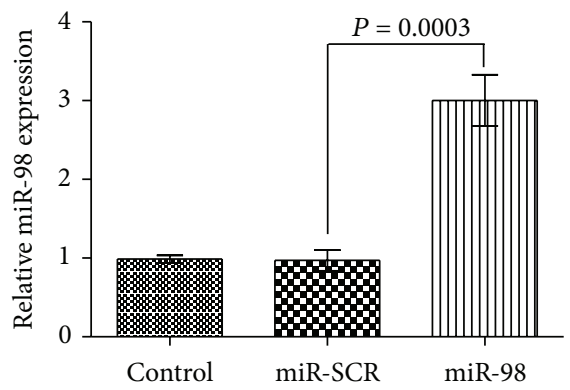

(b)

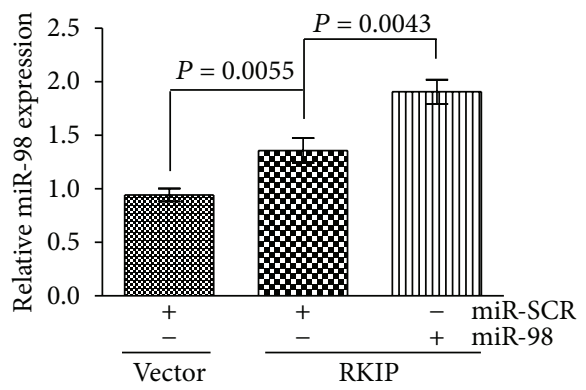

(c)
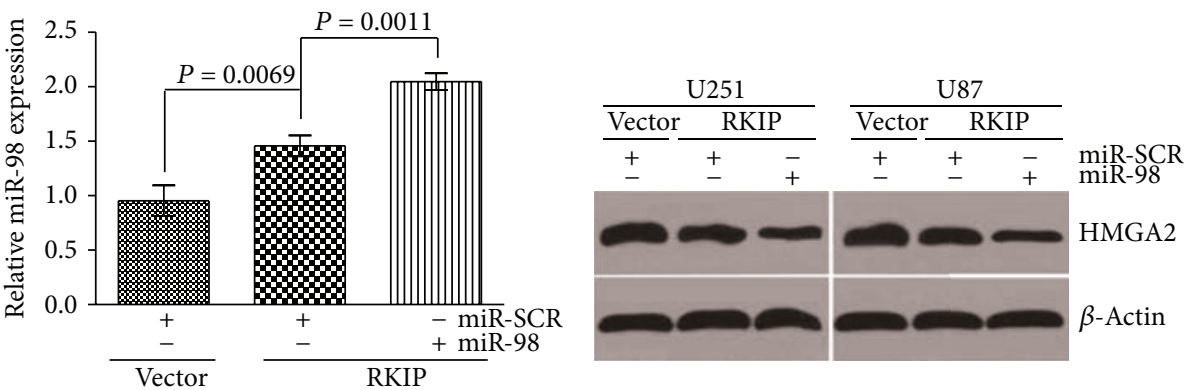

(d)

(e)

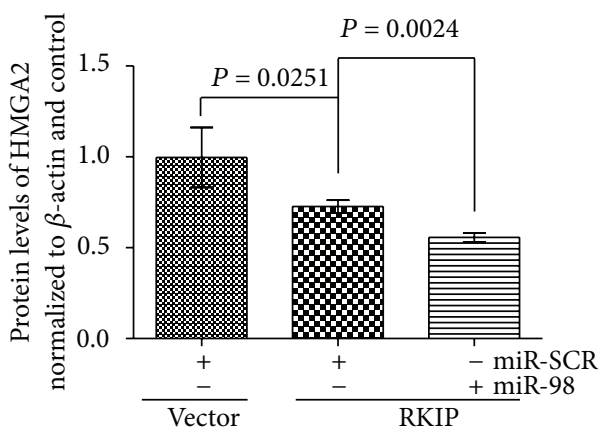

(f)

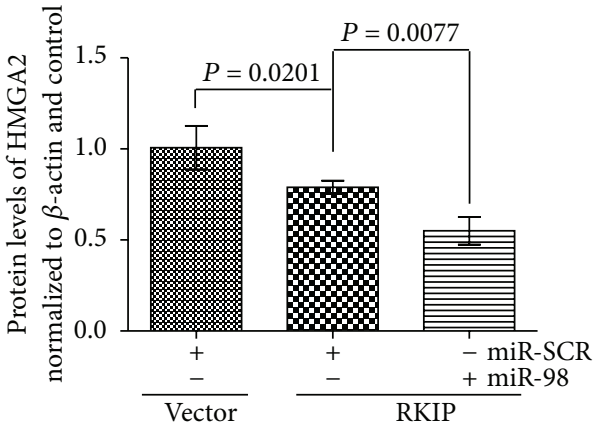

(g)

FIGURE 5: Overexpression of miR-98 enhances the effects of RKIP on miR-98 expression and HMGA2 expression. U251 or U87 cell line was cotransfected with RKIP ORF clone and miR-98 mimics. After $48 \mathrm{~h}$, the level of miR-98 or HMGA2 protein was analyzed by quantitative RTPCR or western blot. (a) Overexpression of miR-98 increased miR-98 expression. (b) Overexpression of miR-98 enhances the effects of RKIP on miR-98 expression. (c) Overexpression of miR-98 increased the effects of RKIP on HMGA2 protein expression. ((d), (e)) Band intensities were quantitated by Image-Pro Plus. The intensities of the bands corresponding to HMGA2 were compared to those corresponding to $\beta$-actin and control cotransfected with miR-SCR and pcDNA3.1 vector. The figure is representative of three experiments with similar results.

4.3. RKIP Inhibits HMGA2 Expression via miR-98 Signaling. To further study the relationship of RKIP and miR-98, we transfected U251 and U87 cells with RKIP ORF clone. Quantitative RT-PCR showed that, at $72 \mathrm{~h}$ after transfection, the expression of miR-98 and RKIP was upregulated as compared with vector (Figures 4(a), 4(b), 4(c), and 4(d)) both in U251 and U87. Moreover, we observed the enhanced RKIP in the two cells significantly repressed HMGA2 protein expression compared to cells transfected with vector control by western blot (Figures 4(c) and 4(e)). Meanwhile, we forced the two cells overexpression of miR-98 by transfecting with miR-98 mimics (Figure 5(a)). When we co-transfected with RKIP ORF clone and miR-98 mimics in the two cells, more apparent up-regulation of miR-98 relative expression was observed by quantitative RT-PCR (Figure 5(b)), and more significant inhibition of HMGA2 protein expression was tested by western blot assay (Figures 5(c) and 5(d)). These data suggested that a potential regulation of miR-98 by RKIP and RKIP might inhibit HMGA2 expression via miR-98 signaling.

\subsection{Effect of RKIP/miR-98 Axis on Glioma Cells Proliferation} and Invasion. To validate if RKIP regulates glioma cells growth and invasion, we performed a proliferation assay (BrdU Assay) by transfecting RKIP or vector control into U251 and U87 cells. It showed that over-expression of RKIP had no effect on cell growth (Figure 6(a)). As shown in Figure 6(b), compared to the vector control, RKIP ORF clone transfected into U251 or U87 cells exhibited significant 


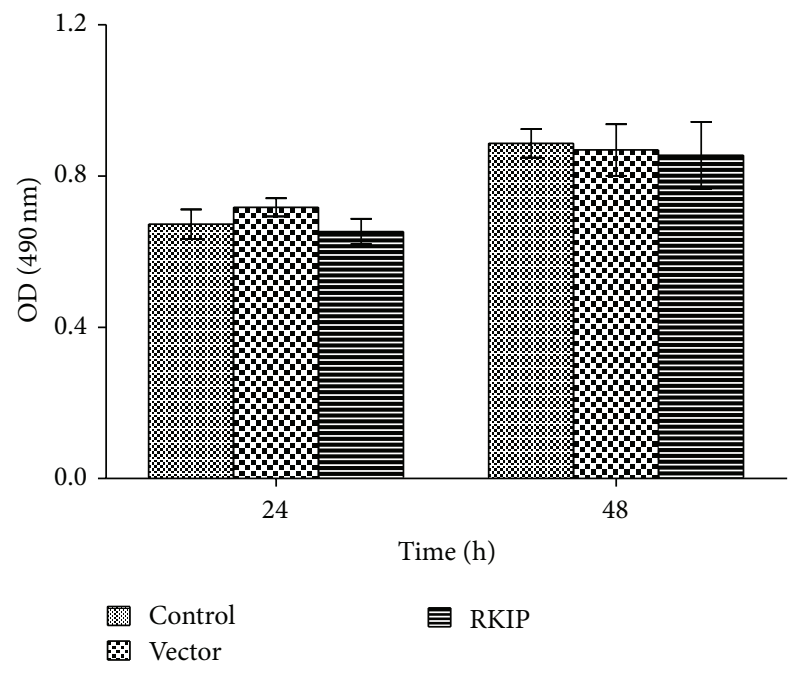

(a)

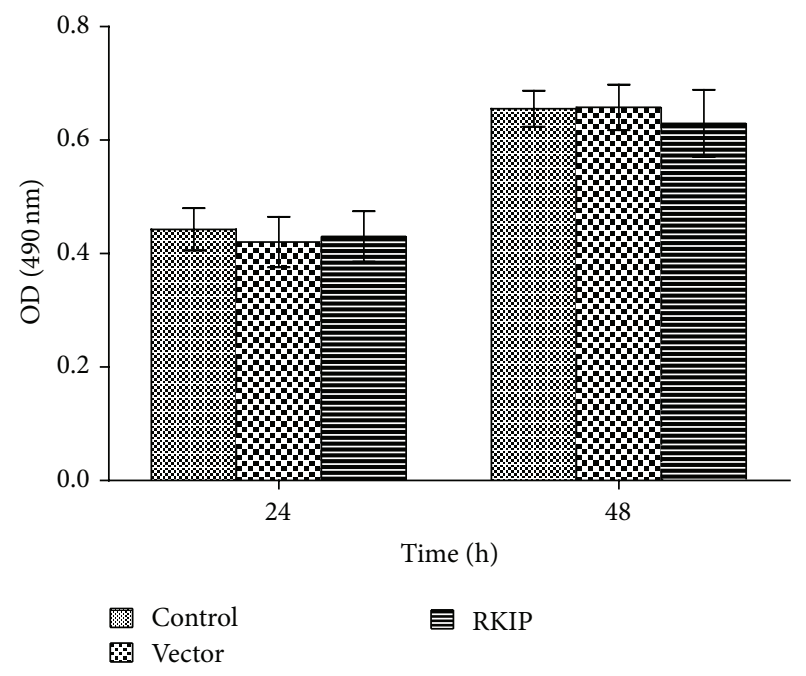

(b)

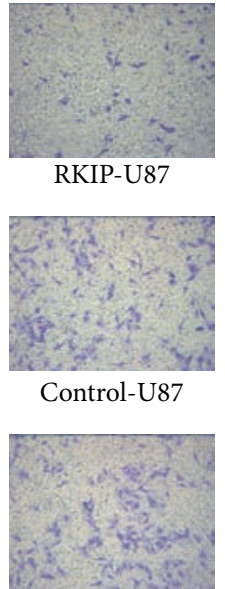

Vector-U87

(c)

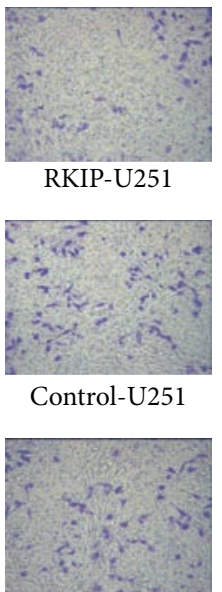

Vector-U251

(d)

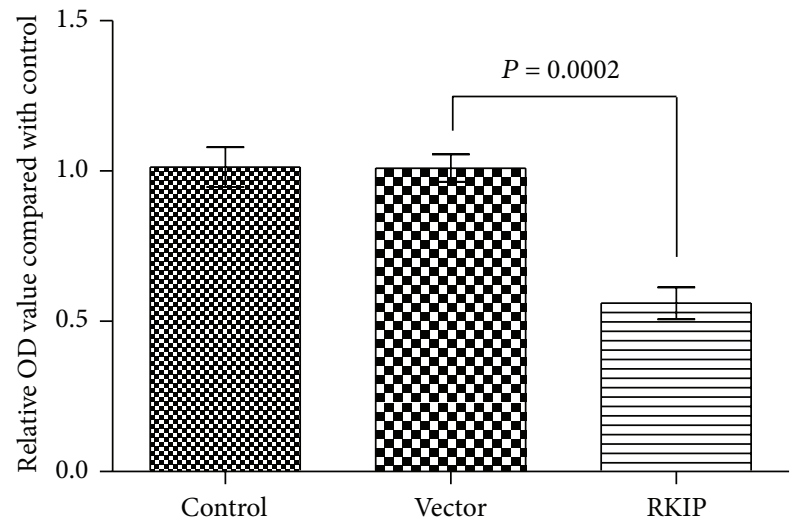

(e)

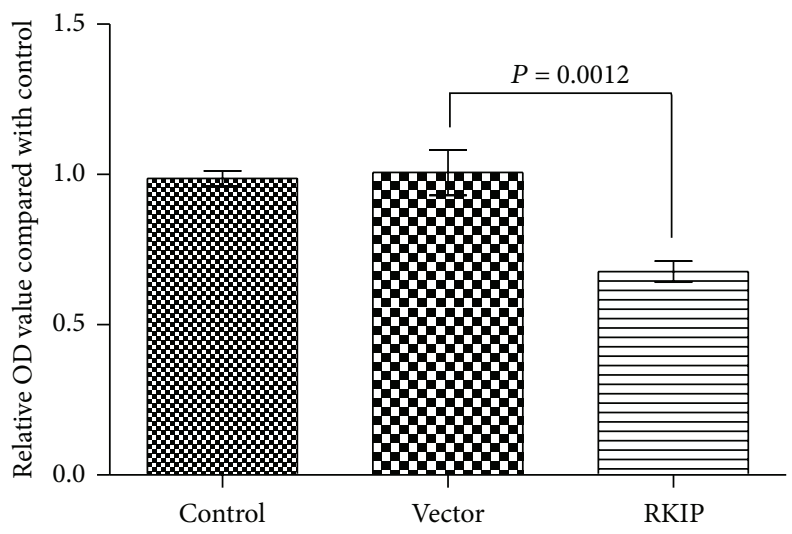

(f)

FIGURE 6: Effects of RKIP on the proliferation and invasion of U251 and U87 cell lines. U251 or U87 cell line was transfected with vector control and RKIP ORF clone. (a) BrdU cell proliferation assay. Ectopic overexpression of RKIP had no effect on proliferation of U251 or U87 cell line, compared to vector ((b), (c)) Transwell assay; upregulated RKIP expression significantly inhibited the invasion ability of U251 and U87 cell lines. The figure is representative of three experiments with similar results. 


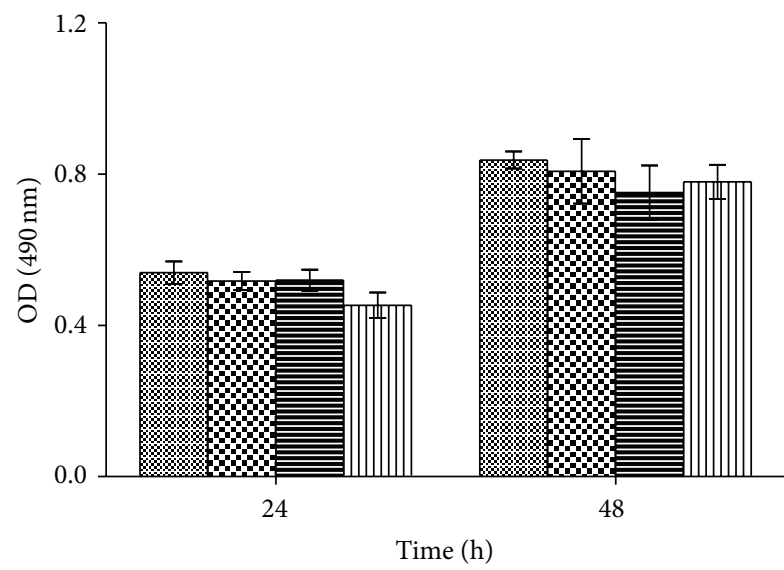

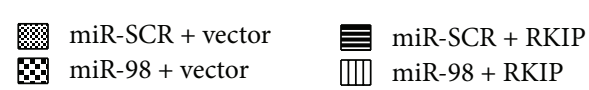

(a)

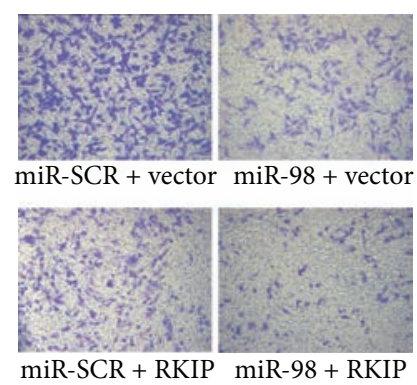

(c)

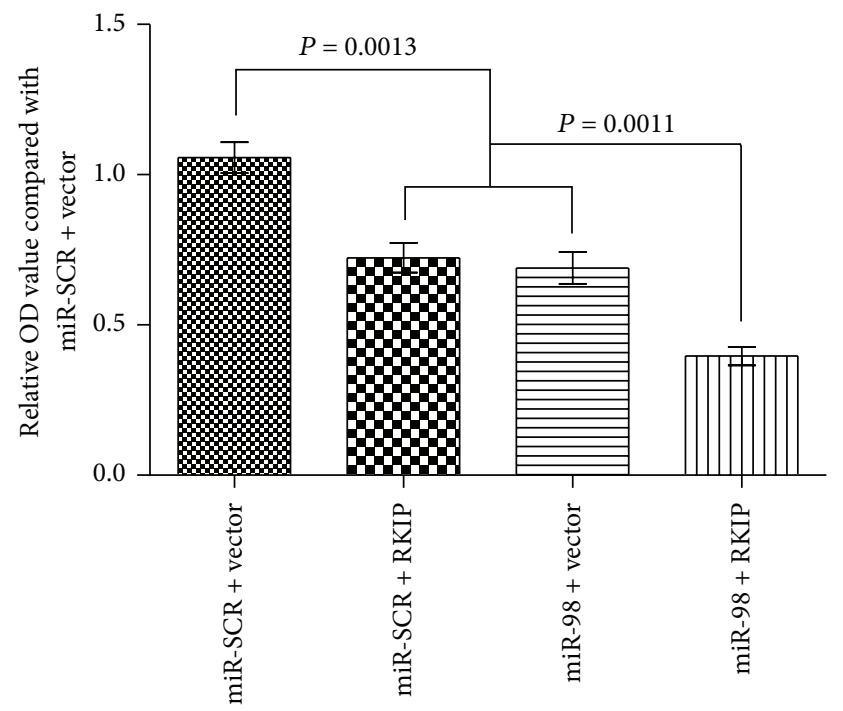

(e)

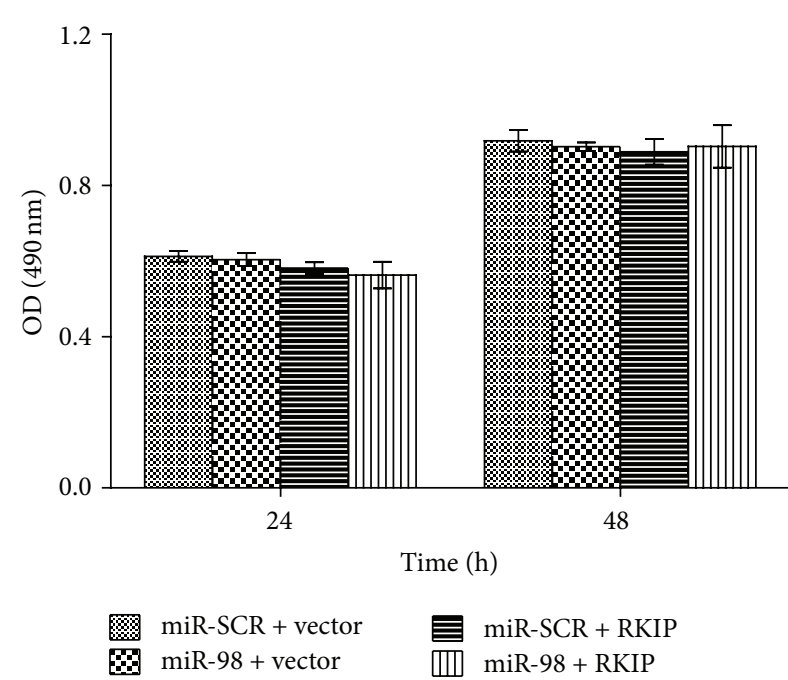

(b)
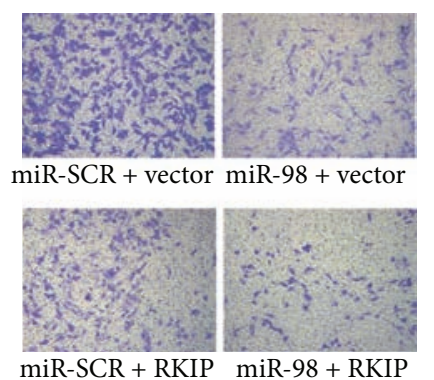

(d)

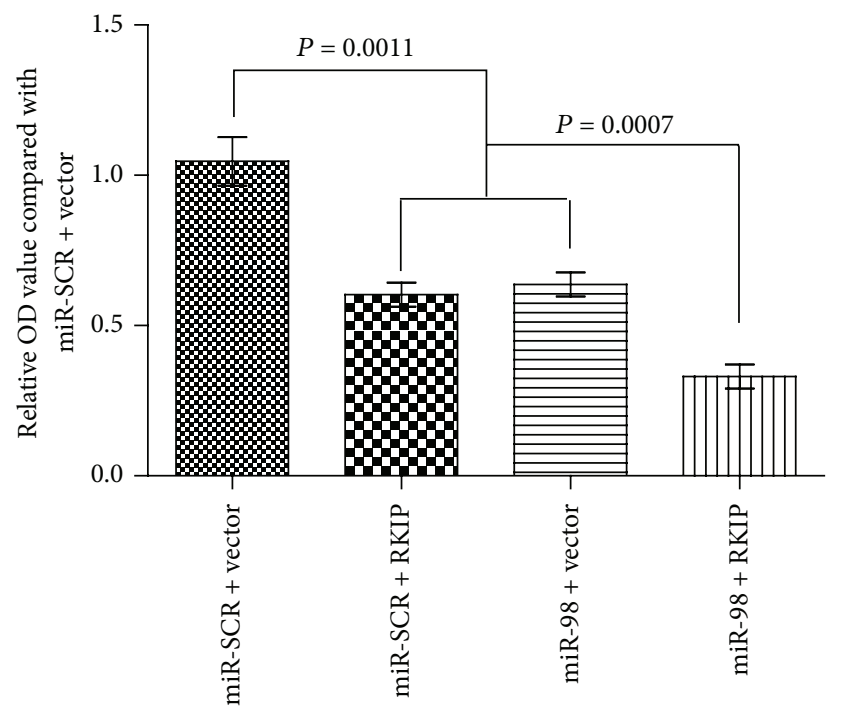

(f)

FIGURE 7: Overexpression of miR-98 enhances effects of RKIP on the proliferation and invasion of U251 or U87 cell line. U251 and U87 cells were cotransfected with RKIP ORF clone and miR-98. After $48 \mathrm{~h}$, the proliferation of U251 or U87 was analyzed by BrdU assay and the invasion ability was observed by Transwell assay. (a) BrdU cell proliferation assay. Overexpression of miR-98 had no effects on the proliferation of U251 or U87 cell line. (b) More significant inhibition of invasion ability was observed by Transwell assay. The figure is representative of three experiments with similar results. 
inhibition of invasion ability (Figures 6(b) and 6(c)). On the other hand, RKIP ORF clone and miR-98 mimics cotransfected into the two glioma cells; also, no proliferation of the cells was observed (Figure 7(a)), but more significant inhibition of invasion ability was tested by Transwell assay (Figures 7(b) and 7(c)). These results indicated that RKIP functions as a potent tumor invasion repression gene through regulating miR-98 expression.

\section{Discussion}

Diffusely infiltrating gliomas are one of the most devastating cancers because they often show locally aggressive behavior and cannot be cured by existing therapies [18]. Like cancer in general, gliomas develop as a result of genetic alterations that accumulate throughout tumor progression $[1,19,20]$. Therefore, the elucidation of these molecular mechanisms, in particular the ones associated with cellular migration and invasion is crucial for a better prediction of glioma patients outcome and response to therapies [21].

RKIP is widely expressed in normal human tissues and has been studied for several years as an important regulator of several physiologic processes [22]. In addition, it is an important regulator of tumor cell invasion and metastasis [22-24]. Furthermore, it was reported to be a prognostic biomarker for a number of tumors including prostate, colorectal, GISTs, gastric adenocarcinoma of the intestinal subtype, hepatocellular carcinoma, pancreatic ductal adenocarcinoma and also in high grade gliomas [25-30]. miR-98 belongs to the mature let-7 family of miRNAs [31] and was initially found to be down regulated in leukemia cell lines [32]. Subsequent studies showed that the expression of miR-98 was also significantly decreased in solid tumors such as nasopharyngeal carcinoma and head and neck squamous cell carcinoma $[33,34]$. In this study, we found the expression of RKIP and miR-98 in glioma tissues was significantly lower and HMGA2 was higher than that in normal brain tissues. These findings showed that miR98 and HMGA2 might participate in regulating tumor cell invasion like RKIP.

On the other hand, over-expression of RKIP up-regulated miR-98 expression and inhibited glioma cell invasion but had no effect on glioma cell proliferation. How does RKIP regulate miR-98? miR-98 expression can be controlled at multiple levels, including synthesis of the primary transcript, Drosha processing to the precursor, and Dicer processing to the mature form [35]. Analysis of the miR-98 primary transcript by qRT-PCR showed an increase in response to RKIP, indicating that regulation occurs subsequent to primary transcription.

Our present findings are in accordance with previous reports in other types of tumors, where RKIP seems to be more important in migration of the cells, instead of as a proliferation suppressor [36-38]. Additionally, we find that RKIP inhibits miR-98 target gene HMGA2 which enhances invasion and regulates a number of target genes that contribute to invasion and metastasis in the glioma cell lines. Moreover, forced expression of miR-98 accelerated the inhibition of glioma cell invasion, and the expression of
HMGA2 also had no effect in glioma cell proliferation. These results suggested that the RKIP/miR-98 to HMGA2 axis might play an important role in inhibiting glioma invasion and metastasis.

The RKIP/miR-98 to HMGA2 axis likely identifies a subpopulation of high-risk human gliomas by revealing a cellular signaling environment that is favourable to metastatic progression. Similar to other tumour suppressors, RKIP loss alone is not sufficient to promote invasion and metastasis unless RKIP depletion occurs in certain cellular signaling contexts. Finally, it is likely that the miR-98 pathway is one of the mechanisms by which RKIP regulates tumor cell invasion. Detailed investigation of genes that comprise the RKIP network should yield further insight into the mechanism by which RKIP suppresses metastatic progression. In conclusion, we newly described RKIP/miR-98/HGMA2 link and provided a potential mechanism for RKIP over-expression and contribution to gliomas invasion but not proliferation. On the other hand, restoration of miR-98 expression could have an important implication for the clinical management of gliomas.

\section{References}

[1] J. T. Huse and E. C. Holland, "Targeting brain cancer: advances in the molecular pathology of malignant glioma and medulloblastoma," Nature Reviews Cancer, vol. 10, no. 5, pp. 319-331, 2010.

[2] S. L. Holmen and B. O. Williams, "Essential role for Ras signaling in glioblastoma maintenance," Cancer Research, vol. 65, no. 18, pp. 8250-8255, 2005.

[3] J. Jeuken, C. van de Broecke, S. Gijsen, S. Boots-Sprenger, and P. Wesseling, "RAS/RAF pathway activation in gliomas: the result of copy number gains rather than activating mutations," Acta Neuropathologica, vol. 114, no. 2, pp. 121-133, 2007.

[4] L. Goldberg and Y. Kloog, "A Ras inhibitor tilts the balance between Rac and Rho and blocks phosphatidylinositol 3-kinase-dependent glioblastoma cell migration," Cancer Research, vol. 66, no. 24, pp. 11709-11717, 2006.

[5] A. B. Hjelmeland, K. P. Lattimore, B. E. Fee et al., "The combination of novel low molecular weight inhibitors of RAF (LBT613) and target of rapamycin (RAD001) decreases glioma proliferation and invasion," Molecular Cancer Therapeutics, vol. 6, no. 9, pp. 2449-2457, 2007.

[6] L. Zeng, A. Imamoto, and M. R. Rosner, "Raf kinase inhibitory protein (RKIP): a physiological regulator and future therapeutic target," Expert Opinion on Therapeutic Targets, vol. 12, no. 10, pp. $1275-1287,2008$.

[7] A. E. Granovsky and M. R. Rosner, "Raf kinase inhibitory protein: a signal transduction modulator and metastasis suppressor," Cell Research, vol. 18, no. 4, pp. 452-457, 2008.

[8] J. Klysik, S. J. Theroux, J. M. Sedivy, J. S. Moffit, and K. Boekelheide, "Signaling crossroads: the function of Raf kinase inhibitory protein in cancer, the central nervous system and reproduction," Cellular Signalling, vol. 20, no. 1, pp. 1-9, 2008.

[9] J. Yun, C. A. Frankenberger, W.-L. Kuo et al., "Signalling pathway for RKIP and Let-7 regulates and predicts metastatic breast cancer," EMBO Journal, vol. 30, no. 21, pp. 4500-4514, 2011.

[10] S. Dangi-Garimella, J. Yun, E. M. Eves et al., "Raf kinase inhibitory protein suppresses a metastasis signalling cascade 
involving LIN28 and let-7," EMBO Journal, vol. 28, no. 4, pp. 347-358, 2009.

[11] C. Hebert, K. Norris, M. A. Scheper, N. Nikitakis, and J. J. Sauk, "High mobility group A2 is a target for miRNA-98 in head and neck squamous cell carcinoma," Molecular Cancer, vol. 6, pp. 5$16,2007$.

[12] K. Motoyama, H. Inoue, Y. Nakamura, H. Uetake, K. Sugihara, and M. Mori, "Clinical significance of high mobility group A2 in human gastric cancer and its relationship to let-7 MicroRNA family," Clinical Cancer Research, vol. 14, no. 8, pp. 2334-2340, 2008.

[13] A. C. Hristov, L. Cope, M. D. Reyes et al., "HMGA2 protein expression correlates with lymph node metastasis and increased tumor grade in pancreatic ductal adenocarcinoma," Modern Pathology, vol. 22, no. 1, pp. 43-49, 2009.

[14] B. Meyer, S. Loeschke, A. Schultze et al., "HMGA2 overexpression in non-small cell lung cancer," Molecular Carcinogenesis, vol. 46, no. 7, pp. 503-511, 2007.

[15] G. Chiappetta, A. Ferraro, E. Vuttariello et al., "HMGA2 mRNA expression correlates with the malignant phenotype in human thyroid neoplasias," European Journal of Cancer, vol. 44, no. 7, pp. 1015-1021, 2008.

[16] J. Miyazawa, A. Mitoro, S. Kawashiri, K. K. Chada, and K. Imai, "Expression of mesenchyme-specific gene HMGA2 in squamous cell carcinomas of the oral cavity," Cancer Research, vol. 64, no. 6, pp. 2024-2029, 2004.

[17] A. Malek, E. Bakhidze, A. Noske et al., "HMGA2 gene is a promising target for ovarian cancer silencing therapy," International Journal of Cancer, vol. 123, no. 2, pp. 348-356, 2008.

[18] A. Claes, A. J. Idema, and P. Wesseling, "Diffuse glioma growth: a guerilla war," Acta Neuropathologica, vol. 114, no. 5, pp. 443458, 2007.

[19] D. N. Louis, H. Ohgaki, O. D. Wiestler et al., “The 2007 WHO classification of tumours of the central nervous system," Acta Neuropathologica, vol. 114, no. 2, pp. 97-109, 2007.

[20] P. Y. Wen and S. Kesari, "Malignant gliomas in adults," The New England Journal of Medicine, vol. 359, no. 5, pp. 492-507, 2008.

[21] D. B. Hoelzinger, T. Demuth, and M. E. Berens, "Autocrine factors that sustain glioma invasion and paracrine biology in the brain microenvironment," Journal of the National Cancer Institute, vol. 99, no. 21, pp. 1583-1593, 2007.

[22] E. T. Keller, Z. Fu, and M. Brennan, "The role of Raf kinase inhibitor protein (RKIP) in health and disease," Biochemical Pharmacology, vol. 68, no. 6, pp. 1049-1053, 2004.

[23] E. T. Keller, "Metastasis suppressor genes: a role for raf kinase inhibitor protein (RKIP)," Anti-Cancer Drugs, vol. 15, no. 7, pp. 663-669, 2004.

[24] E. T. Keller, Z. Fu, and M. Brennan, "The biology of a prostate cancer metastasis suppressor protein: raf kinase inhibitor protein," Journal of Cellular Biochemistry, vol. 94, no. 2, pp. 273-278, 2005.

[25] H.-S. Kim, G. Y. Kim, S.-J. Lim, and Y. W. Kim, "Loss of Raf-1 kinase inhibitory protein in pancreatic ductal adenocarcinoma," Pathology, vol. 42, no. 7, pp. 655-660, 2010.

[26] Y.-F. Xu, Y. Yi, S.-J. Qiu et al., "PEBP1 downregulation is associated to poor prognosis in HCC related to hepatitis B infection," Journal of Hepatology, vol. 53, no. 5, pp. 872-879, 2010.

[27] D. Chatterjee, E. Sabo, R. RosemarieTavares, and M. B. Resnick, "Inverse association between raf kinase inhibitory protein and signal transducers and activators of transcription 3 expression in gastric adenocarcinoma patients: implications for clinical outcome," Clinical Cancer Research, vol. 14, no. 10, pp. 29943001, 2008.

[28] O. Martinho, A. Gouveia, P. Silva, A. Pimenta, R. M. Reis, and J. M. Lopes, "Loss of RKIP expression is associated with poor survival in GISTs," Virchows Archiv, vol. 455, no. 3, pp. 277-284, 2009.

[29] O. Martinho, S. Granja, T. Jaraquemada et al., "Downregulation of RKIP is associated with poor outcome and malignant progression in gliomas," PLOS ONE, vol. 7, no. 1, Article ID e30769, 2012.

[30] J. Maresch, P. Birner, M. Zakharinov, K. Toumangelova-Uzeir, S. Natchev, and M. Guentchev, "Additive effect on survival of raf kinase inhibitor protein and signal transducer and activator of transcription 3 in high-grade glioma," Cancer, vol. 117, no. 11, pp. 2499-2504, 2011.

[31] S. Roush and F. J. Slack, “The let-7 family of microRNAs," Trends in Cell Biology, vol. 18, no. 10, pp. 505-516, 2008.

[32] J. Yu, F. Wang, G.-H. Yang et al., "Human microRNA clusters: genomic organization and expression profile in leukemia cell lines," Biochemical and Biophysical Research Communications, vol. 349, no. 1, pp. 59-68, 2006.

[33] C. Hebert, K. Norris, M. A. Scheper, N. Nikitakis, and J. J. Sauk, "High mobility group A2 is a target for miRNA-98 in head and neck squamous cell carcinoma," Molecular Cancer, vol. 6, article 5, 2007.

[34] N. M. Alajez, W. Shi, A. B. Y. Hui et al., "Enhancer of Zeste homolog 2 (EZH2) is overexpressed in recurrent nasopharyngeal carcinoma and is regulated by miR-26a, miR-101, and miR98," Cell Death and Disease, vol. 1, no. 10, article e85, 2010.

[35] W. Wu, M. Sun, G.-M. Zou, and J. Chen, "MicroRNA and cancer: current status and prospective," International Journal of Cancer, vol. 120, no. 5, pp. 953-960, 2007.

[36] S. Dangi-Garimella, J. Yun, E. M. Eves et al., "Raf kinase inhibitory protein suppresses a metastasis signalling cascade involving LIN28 and let-7," EMBO Journal, vol. 28, no. 4, pp. 347-358, 2009.

[37] M. M. Schuierer, F. Bataille, S. Hagan, W. Kolch, and A.K. Bosserhoff, "Reduction in Raf kinase inhibitor protein expression is associated with increased Ras-extracellular signalregulated kinase signaling in melanoma cell lines," Cancer Research, vol. 64, no. 15, pp. 5186-5192, 2004.

[38] Z. Fu, P. C. Smith, L. Zhang et al., "Effects of Raf kinase inhibitor protein expression on suppression of prostate cancer metastasis," Journal of the National Cancer Institute, vol. 95, no. 12 , pp. 878-889, 2003. 

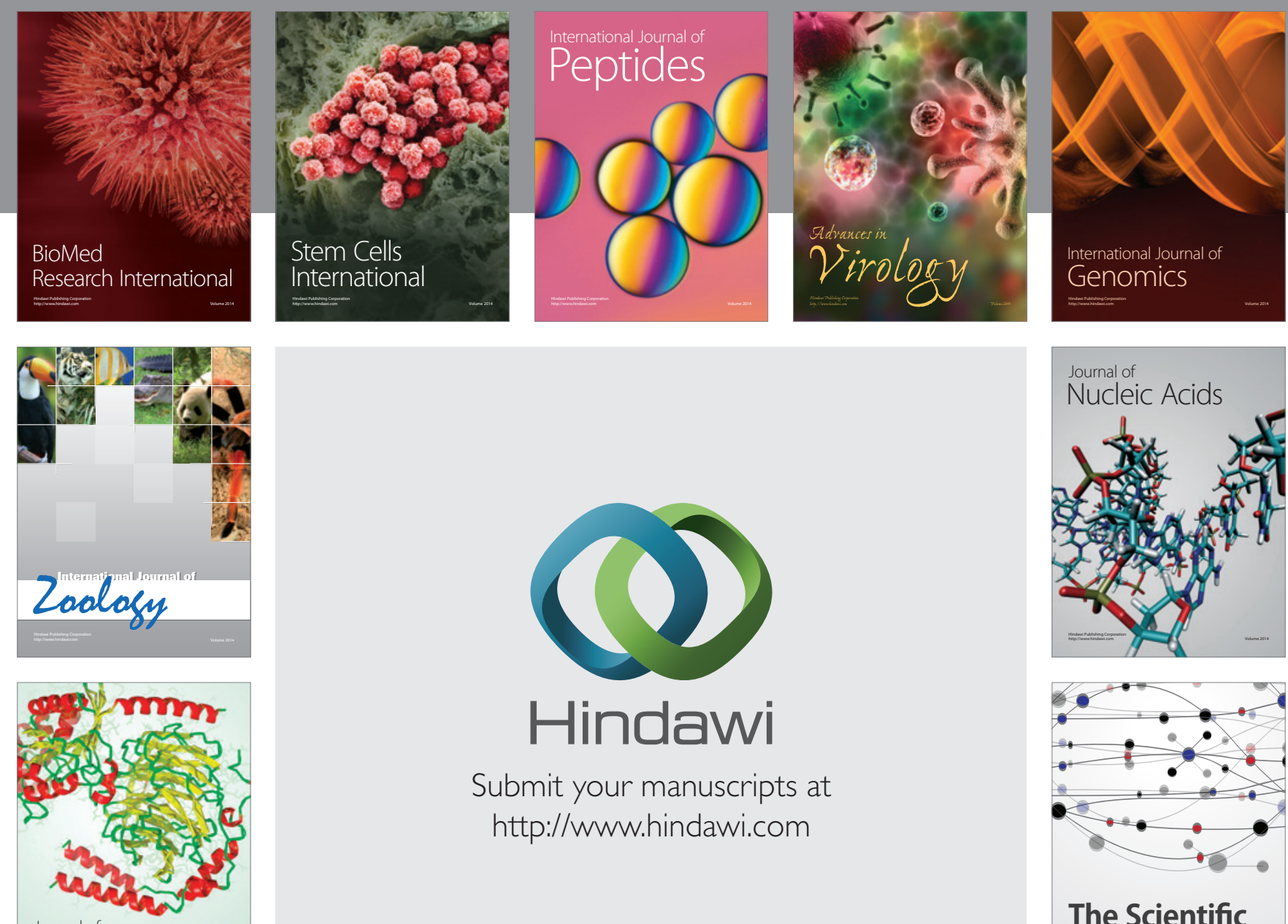

Submit your manuscripts at

http://www.hindawi.com

Journal of
Signal Transduction
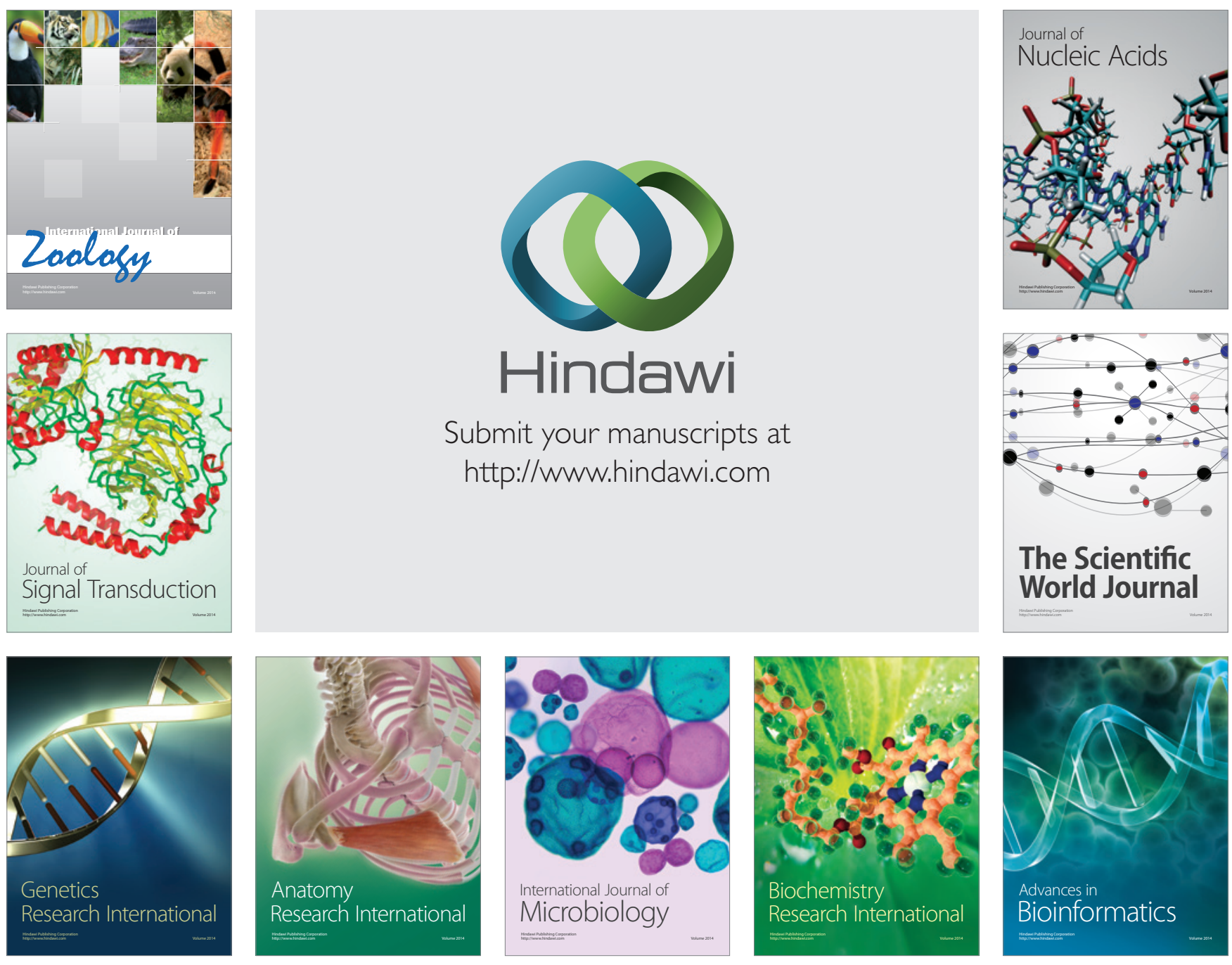

The Scientific World Journal
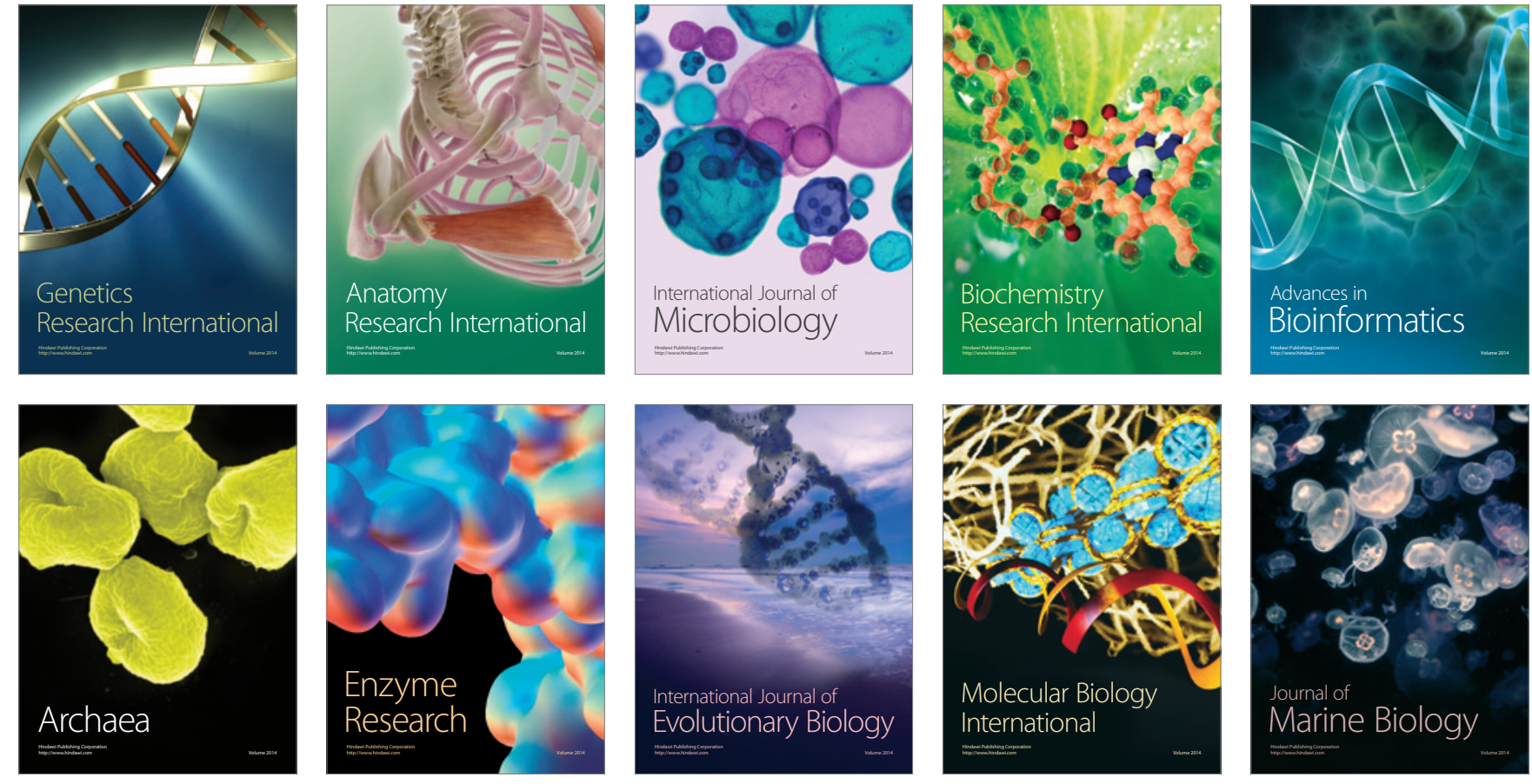